Иевлева Анна Александровна

кандидат экономических наук, доцент кафедры финансов и кредита

Воронежского филиала Российского

экономического университета им. Г.В. Плеханова

\section{БАНКОВСКАЯ ПОЛИТИКА В СФЕРЕ ПРИВЛЕЧЕНИЯ РЕСУРСОВ: ДИСКУССИОННЫЕ АСПЕКТЫ ЭКОНОМИЧЕСКОГО СОДЕРЖАНИЯ}

Аннотация:

В статье на основе анализа дефиниций финансовой и ресурсной политики банка систематизируется понятийный аппарат рассматриваемой области, выявляется соотношение исследуемых категорий, $в$ том числе понятий «депозитная политика», «эмиссионная политика», «политика управления собственным капиталом», «политика привлечения финансовых ресурсов». Сделан вывод, что в современных условиях определение ресурсной политики банка должно отражать комплексное представление о ресурсах как о факторах производства, а не опираться исключительно на их толкование как источников средств. Значимость финансовых ресурсов в деятельности банка, выступающих объектом управления его финансовой политики, потребовала уточнения содержания принципов, методов, мер финансовой политики, а также ее структурных блоков, конкретизированных на основе общих и специфических инструментов финансовой политики.

Ключевые слова:

ресурсы, ресурсная политика, банк, финансовая политика, финансовые ресурсы, инструменты финансовой политики.

\section{levleva Anna Aleksandrovna}

PhD in Economics, Associate Professor, Finance and Credit Department, Voronezh Institute (branch) of

Plekhanov Russian University of Economics

\section{BANKING POLICY OF RESOURCE MOBILIZATION: CONTROVERSIAL ASPECTS OF ECONOMIC SUBSTANCE}

Summary:

The analysis of the definitions of the banking financial and resource policy makes it possible to systematize the conceptual construct of the field under review and reveal the relationship between the terms 'deposit policy', 'issuing policy', 'stockholders' equity management policy', and 'financial resource mobilization policy'. The author concludes that, nowadays, the definition of the bank's resource policy should reflect a comprehensive view on resources as factors of production rather than interpret them only as sources of funds. The significance of banking financial resources that are being managed by the bank's financial policy necessitated clarifying the content of the principles, methods, and measures of the financial policy and its structural units refined on the basis of general and specific financial policy instruments.

Раскрывая экономическое содержание банковской политики в сфере привлечения ресурсов, необходимо систематизировать имеющийся в финансовой литературе понятийный аппарат рассматриваемой предметной области, который включает категории финансовой, ресурсной, депозитной, эмиссионной политики банка, а также политики формирования привлеченных ресурсов. Перечисленные виды политик, за исключением депозитной, применимы не только в банковской, но и в иных областях экономической деятельности. Следовательно, нужно конкретизировать их экономическое содержание применительно к банкам и их деятельности.

Если рассматривать политику в целом как искусство управления, рациональную целенаправленную деятельность, осуществляемую для выявления и решения проблем, стоящих перед государством и субъектами экономики, то следует говорить о ней как о сложном явлении, характерном для различных областей, уровней, целей, а также субъектов ее реализации.

Финансовая политика относится к сфере создания, движения финансовых потоков, образования и применения фондов денежных средств и реализуется на макро-, мезо- и микроуровнях. В частности, А.Г. Грязнова с соавторами определяют финансовую политику на макроуровне как «совокупность целенаправленных мер государства в области использования финансов с целью определения... эфффективных... мероприятий для создания финансовой основы реализации экономической политики государства» [1, с. 41].

Финансовая политика на макроуровне служит средством, с помощью которого формируется финансовая основа достижения целей, стоящих перед государством. Финансовой основой выступают фринансовые ресурсы, фрормируемые и используемые в ходе фринансовых отношений между государством и субъектами экономики. Финансовая политика макроуровня охватывает два ключевых аспекта - финансовое обеспечение деятельности государства и достижение общественно значимых целей. Государственная финансовая политика должна базироваться на трех элементах: 1) концепция развития фринансовых отношений; 2) ключевые направления применения фринансовых ресурсов 
в рамках текущего периода; 3) конкретизация направлений использования финнансовых ресурсов в будущем. Второй элемент содержания фринансовой политики относится к финансовой тактике, а третий - к финансовой стратегии. Финансовая тактика как оперативная составляющая финансовой политики реализуется в рамках финансовой стратегии, описывающей систему долговременных целей и задач в области фринансовых отношений.

Понимание финансовой политики как единства финансовой стратегии и тактики в ходе раскрытия ее экономического содержания на микроуровне - явление, довольно часто встречающееся в отечественной экономической литературе. Однако само толкование стратегии, как и политики, выходит за рамки финансовой составляющей. Считается, что понятие стратегии применительно к предприятию впервые ввел А.Д. Чандлер, согласно ему стратегия связана с определением долгосрочных целей и задач компании, утверждением курса действий и распределением ресурсов, необходимых для достижения этих целей [2, р. 5]. Базируясь на концепции сущности банка как особого финансово-кредитного предприятия, считаем данную дефиницию справедливой и для банка. Со времен первоначальной формулировки содержания стратегии организации прошло много времени. Однако она не потеряла актуальности в силу заложенной основополагающей концепции трактовки. Все последующие подходы к стратегии, на наш взгляд, были направлены на уточнение лежащих в ее основе целей, задач и курса действий.

Итак, основой реализации стратегии являются ресурсы (в экономической теории - факторы производства). Ресурсы, используемые для достижения целей, многообразны: это не только финансовые ресурсы, но и информационные, трудовые, технологические, материальнотехнические и др. Соответственно, к финансовой стратегии и связанной с ней финансовой политике относятся исключительно вопросы фрормирования и распределения финансовых ресурсов. В свою очередь финансовые ресурсы могут трансформироваться в любой другой вид ресурсного обеспечения деятельности экономического субъекта.

Активизация цифровых технологий в банковской сфере все в большей степени усиливает значимость всех составляющих ресурсов банка. Внедрение цифровых инноваций требует достижения баланса ресурсов, в том числе трудовых и финансовых, модернизации банковской структуры, продуктов и каналов взаимодействия с клиентами и т. п., а также изменения взглядов на содержание политики банка в области ресурсов соответственно. Тем не менее современная российская экономическая литература, как правило, не учитывает широкое толкование ресурсной составляющей (таблица 1).

\section{Таблица 1 - Основания дефиниции финансовой и ресурсной политики банка} в экономической литературе

\begin{tabular}{|c|c|}
\hline Финансовая политика банка & Ресурсная политика банка \\
\hline \multicolumn{2}{|c|}{ 1. Политика как инструмент управления } \\
\hline $\begin{array}{l}\text { Внутрибанковская императивная система денежных от- } \\
\text { ношений, задаваемая на основе принятой идеологии } \\
\text { собственниками... по поводу управления денежными } \\
\text { ресурсами в целях максимизации прибыли и обеспече- } \\
\text { ния требуемого уровня благосостояния собственников } \\
\text { при условии сохранения... статуса постоянно действу- } \\
\text { ющего конкурентоспособного и инвестиционно привле- } \\
\text { кательного коммерческого банка [3, с. 1137] }\end{array}$ & $\begin{array}{l}\text { Совокупность регламентированных и интегриро- } \\
\text { ванных в корпоративную стратегию мероприятий } \\
\text { по фрормированию ресурсного капитала, позво- } \\
\text { ляющих банку эффективно реализовывать в ры- } \\
\text { ночной экономике присущие ему функции фри- } \\
\text { нансового посредника и обеспечивающих транс- } \\
\text { формацию аккумулируемых средств в капитал } \\
\text { как самовозрастающую стоимость [7, с. 19] }\end{array}$ \\
\hline $\begin{array}{l}\text { Определяет направления развития в области форми- } \\
\text { рования и трансформации финансовых ресурсов юри- } \\
\text { дических и ффизических лиц; стратегия и тактика банка } \\
\text { в области формирования и трансформации финансо- } \\
\text { вых ресурсов [4, с. 50-51] }\end{array}$ & $\begin{array}{l}\text { Стратегия и тактика в сфере определения ста- } \\
\text { бильных и срочных денежных источников как } \\
\text { для фрормирования собственных, так и для при- } \\
\text { влечения денежных средств со стороны, чтобы } \\
\text { обеспечить прибыльность, надежность и лик- } \\
\text { видность банка [8, с. 209] }\end{array}$ \\
\hline $\begin{array}{l}\text { Связана с управлением финансовой устойчивостью, } \\
\text { ориентирована как на текущие потребности банка, так } \\
\text { и на перспективные цели [5, с. } 57]\end{array}$ & \multirow{2}{*}{$\begin{array}{l}\text { Анализ депозитов, сокращение расходов в ходе } \\
\text { привлечения денежных средств, оптимизация } \\
\text { управления депозитным портфелем банка для } \\
\text { повышения его устойчивости и поддержания не- } \\
\text { обходимого уровня ликвидности }[9, \text { с. } 44]\end{array}$} \\
\hline $\begin{array}{l}\text { Инструмент банковского фринансового менеджмента, } \\
\text { используемого субъектами управления при воздей- } \\
\text { ствии на фринансовые объекты [6] }\end{array}$ & \\
\hline \multicolumn{2}{|c|}{ 2. Политика как совокупность процессов/процедур } \\
\hline $\begin{array}{l}\text { Принципы и методы выполнения последовательно } \\
\text { связанных действий по формированию и трансформа- } \\
\text { ции фринансовых ресурсов банка в целях выполнения } \\
\text { функций банка... в различных экономических условиях } \\
{[10, \text { с. 71] }}\end{array}$ & $\begin{array}{l}\text { Привлечение необходимого объема средств и } \\
\text { трансформация их в банковские ресурсы с } \\
\text { наименьшими затратами }[11, \text { с. } 72]\end{array}$ \\
\hline
\end{tabular}


Более того, данные таблицы 1 свидетельствуют, что понятия финансовой и ресурсной политики часто заменяют друг друга. Исследователи видят их идентичными по сути и содержанию, что, наш взгляд, концептуально неверно. Также отдельные авторы, выделяя ресурсную политику в качестве объекта анализа, ошибочно ограничивают ее содержание депозитными ресурсами.

Считаем, что толкование ресурсной политики должно выходить за рамки известной учетноаналитической трактовки ресурсов как источников средств, которая прослеживается в каждой из приведенных дефиниций. Под ресурсной политикой коммерческого банка, по нашему мнению, целесообразно понимать стратегию и тактику банка в области эффективного фрормирования и использования трудовых, материальных, фринансовых, организационных, информационных и других ресурсов банка в разрезе реализуемых направлений банковской деятельности в соответствии с установленными приоритетами и целями учреждения. Соответственно, фринансовая политика является составляющей ресурсной политики банка, ее разновидностью наряду с кадровой политикой, политикой управления материально-технической базой и политикой управления информационными и цифровыми ресурсами. Каждый из элементов ресурсной политики кредитной организации представляется самостоятельным предметом исследования в силу специфики объекта управления. Остановимся более подробно на базовых аспектах финансовой политики банка.

Неоднозначность суждений исследователей по поводу существа финансовой политики банка (см. таблицу 1) необходимо систематизировать и уточнить. В частности, при определении финансовой политики банка должны быть выделены такие существенные, на наш взгляд, аспекты: 1) разрабатывается на уровне высшего менеджмента банка и отвечает интересам собственников, в том числе в вопросах устойчивого функционирования банка в долгосрочной перспективе; 2) основана на фринансовой стратегии и тактике, которые уточняют цели фринансовой деятельности; 3) конкретизирует принципы, меры и методы в сфере финансового обеспечения банковской деятельности, в том числе в направлении эфффективной трансформации финансовых ресурсов в активы организации; 4) фриксируется документально, обязательна в течение периода действия; 5) учитывает специфику кредитного учреждения как фринансового посредника.

По мнению О.С. Мирошниченко, дефиниции финансовой политики банка в современных исследованиях базируются на различных подходах, а именно на процессно-процедурном, целеориентированном, документарном [12]. В настоящем исследовании мы придерживаемся первого. В соответствии с ним и имеющимися наработками финансовую политику банка предлагаем трактовать как систему принципов, мер и методов, лежащих в основе процессов и процедур организации фринансового обеспечения деятельности коммерческого банка, направленного на достижение целей и задач собственников банка с учетом требований его устойчивого функционирования в перспективе как финансового посредника. Под принципами мы понимаем правила формирования и реализации финансовой политики, на которых строится выбор мер и методов, используемых в ходе организации фринансового обеспечения банковской деятельности. Их следует отнести к принципам управления фринансами банка, поскольку при фрормулировании фринансовой стратегии и тактики они должны быть количественно измерены.

В экономической литературе выделяются общие и специфические принципы финансовой политики банка. Приведенные в работе Е.Г. Шатковской принципы приоритетности целей собственников, действенности, согласованности интересов субъектов управления могут трактоваться как общие [13]. Однако считаем, что их целесообразно объединить в рамках принципа системности. Он означает, что политика должна учитывать взаимное влияние банковских рисков, структуры и стоимости фринансовых ресурсов на структуру и стоимость формируемых активов банка. Именно его соблюдение позволит повысить эфффективность финансового взаимодействия с кредитным учреждением всех участников процесса финансового обеспечения его деятельности, а также нивелировать противоречия между ними, которые неоправданно недооценивает указанный автор, говоря о «первичности интересов субъектов управления» [14, с. 1141]. Значимость принципа системности подтверждается и эмпирическими исследованиями. В частности, при оценке стоимости банковского капитала показано, что «повышение эфффективности затрат, кредитный риск и размер банка являются наиболее важными факторами, объясняющими создание акционерной стоимости» [15].

Кроме того, к общим принципам, на наш взгляд, следует отнести принципы единства (принятая банком политика должна реализовываться субъектами разных уровней управления), непрерывности (политика должна быть адекватна внутренней и внешней средам функционирования кредитной организации, но ее пересмотр должен быть обоснован и утвержден). Именно в предлагаемой нами трактовке обозначенные принципы способствуют повышению эфффективности формирования и использования фринансовых ресурсов коммерческого банка.

Специфические принципы фринансовой политики определены, например, в работах Е.А. Бибиковой, С.В. Симонцевой [16], С.А. Орловой, Е.С. Ташановой [17] и др.

Как и любая другая политика банка, финансовая политика характеризуется конкретным объектом управления, а именно финансовыми ресурсами, с помощью которых субъект фринансовой политики (банк) может решать задачи инвестиционно-финансового характера. Их решение 
осуществляется на основе комбинации двух типовых процессов (что очевидно и принято финансовым сообществом) - мобилизации и инвестирования. Результатом мобилизации являются нахождение источников финансирования и привлечение необходимого объема фринансовых ресурсов (средств). Источники финансирования в классическом понимании подразделяются на собственные, заемные и привлеченные, а финансовые средства структурно представляют собой денежные доходы, накопления, поступления. Результатом инвестирования выступают направления и объемы вложения привлеченных средств. Причем последние трактуются широко, в том числе как средства, привлеченные от собственников.

Специфический объект финансовой политики банка мобилизуется и инвестируется на основе конкретных методов. В частности, в работе С.В. Симонцевой отмечается, что в составе финансовых методов, относящихся к финансовой политике банка, выделяются «методы привлечения» [18, с. 78]. Исходя из толкования ресурсов банка как фракторов банковского производства, в контексте финансовой политики целесообразно говорить о методах финансового обеспечения, а именно о методах долгового, долевого и самофинансирования. В свою очередь процессы инвестирования реализуются методами трансформации финансовых ресурсов в ходе проведения активных операций банка.

К мерам финансовой политики банка мы относим специфические мероприятия, направленные на повышение эффективности финансового обеспечения банковской деятельности, например увеличение адекватности собственного капитала, оптимизацию ликвидной позиции банка и т. п. Такое представление о содержании финансовой политики позволяет выделить в ней характерные блоки, раскрывающие объект управления. Ее укрупненными блоками выступают политика привлечения финансовых ресурсов кредитного учреждения, а также политика трансформации его финансовых ресурсов. Учитывая рисковую природу деятельности коммерческого банка, в структуру финансовой политики включен третий блок - политика управления рисками. Все три блока взаимосвязаны и должны представлять собой единое целое, а процессы и процедуры, осуществляемые в рамках каждого блока, должны быть согласованы между собой (рисунок 1).

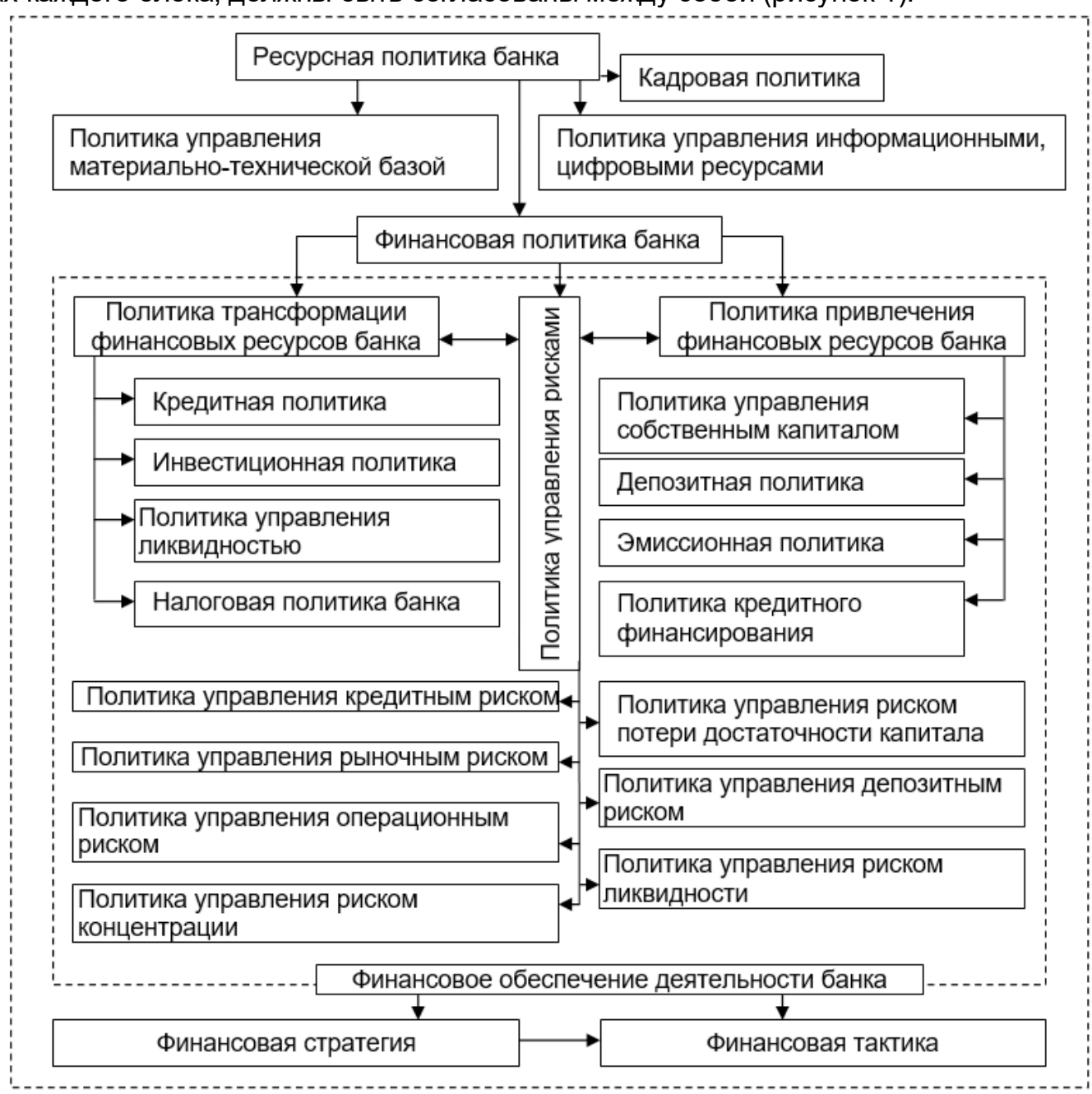

Рисунок 1 - Комплексная структура политики банка в сфере ресурсов [19] 
Дальнейшая детализация укрупненных блоков финансовой политики банка проводится с помощью инструментов воздействия на объект финансовой политики, которые используются в рамках взаимосвязанных процессов мобилизации и трансформации (инвестирования) фринансовых ресурсов. Банк, реализуя финансовую политику, применяет набор общих (свойственных для иных экономических субъектов) и специфических инструментов (характерных исключительно для банка как особого финансового посредника).

К общим инструментам реализации финансовой политики относятся эмиссия ценных бумаг (акций, облигаций, векселей), создание фондов банка (резервного фонда), инвестиционные операции на рынке ценных бумаг, трансформация финансовых ресурсов в налоговые платежи. К специфическим следует отнести привлечение вкладов, депозитов, открытие банковских счетов, выпуск депозитных и сберегательных сертификатов, получение и предоставление межбанковских кредитов, рефинансирование со стороны Центрального банка, кредитование клиентов.

Политика привлечения финансовых ресурсов банка - это часть банковской финансовой политики, реализуемой на основе методов долевого, долгового и самофинансирования с учетом принципов фринансовой политики в ходе осуществления мер, направленных на стимулирование создания адекватного фринансового обеспечения банковской деятельности. Исходя из обозначенных инструментов, выделим в ней ряд блоков, в том числе новый - политика кредитного фиинансирования (таблица 2).

Таблица 2 - Структурные блоки политики привлечения банковских финансовых ресурсов [20]

\begin{tabular}{|l|l|}
\hline \multicolumn{1}{|c|}{ Блок } & \multicolumn{1}{c|}{ Содержание } \\
\hline $\begin{array}{l}\text { Политика управления } \\
\text { собственным капиталом }\end{array}$ & $\begin{array}{l}\text { Раскрывает механизм формирования и поддержания источников собственного } \\
\text { капитала банка, соответствующих требованиям к достаточности банковского ка- } \\
\text { питала для защиты от рисков, а также создания его адекватной стоимости }\end{array}$ \\
\hline Депозитная политика & $\begin{array}{l}\text { Обосновывает использование инструментов депозитного финансирования } \\
\text { для формирования устойчивой депозитной базы оптимальной стоимости }\end{array}$ \\
\hline Эмиссионная политика & $\begin{array}{l}\text { Раскрывает механизм создания ресурсов банка на основе инструментов } \\
\text { рынка ценных бумаг }\end{array}$ \\
\hline $\begin{array}{l}\text { Политика кредитного } \\
\text { финансирования }\end{array}$ & Определяет механизм межбанковского финансирования \\
\hline
\end{tabular}

Политика трансформации финансовых ресурсов банка реализуется в рамках кредитной, инвестиционной, налоговой политики, а также политики управления ликвидностью. Политика управления рисками должна осуществляться с учетом декомпозиции по видам банковских рисков (кредитному, депозитному, риску потери ликвидности и др.).

Таким образом, представление укрупненной структуры политики банка в сфере привлечения ресурсов на основе трактовки ресурсов как факторов банковского производства, по нашему мнению, позволит комплексно управлять ее объектами в направлении повышения эффеективности их использования. Этому, в частности, способствует внедрение функционально-стоимостного анализа в банковскую сферу. Необоснованная, на наш взгляд, подмена понятий в области ресурсной политики банков нарушает систему соотношения объектов управления и может привести к неверно расставленным приоритетам управления на практике, а в теоретическом аспекте - к неадекватному исследованию механизма ресурсного обеспечения банков.

\section{Ссылки и примечания:}

1. Финансы : учебник / А.Г. Грязнова, Е.В. Маркина, М.Л. Седова и др. ; под ред. А.Г. Грязновой, Е.В. Маркиной. 2-е изд., перераб. и доп. М., 2012. 496 c.

2. Chandler A.D. Strategy and Structure. Chapters in the History of the American Industrial Enterprise. Washington, 2003. $480 p$

3. Шатковская Е.Г. Система формирования и реализации финансовой политики кредитной организации // Фундаментальные исследования. 2014. № 11-5. С. 1137-1142.

4. Орлова С.А., Ташанова Е.С. Финансовая политика коммерческого банка // Экономическая среда. 2018. № 3 (25). C. $50-54$.

5. Дувалова Э.П. Управление финансовой политикой коммерческого банка как инструмент повышения его рыночной устойчивости // Казанский экономический вестник. 2012. № 1 (1). С. 57-62.

6. Мирошниченко О.С. Финансовая политика банка: теоретические аспекты [Электронный ресурс] // Управление экономическими системами : электронный журнал. 2014. № 10. URL: http://uecs.ru/finansi-i-kredit/item/3081-2014-10-16-0758-30 (дата обращения: 05.05.2019).

7. Щербинин А.Е. Стратегия формирования пассивов в рамках ресурсной политики регионального банка // Банковские услуги. 2009. № 2. С. 19-24.

8. Годин А., Курилов Р. Ресурсная политика - как основа управления банком // Вестник Института экономики РАН. 2009. № 2. C. 209-214.

9. Селеванова Е.В., Адамчук В.С. Ресурсная политика кредитных организаций // Научные исследования. 2018. № 6 (26). C. 44-46. 
10. Симонцева С.В. Финансовая политика как основа управления финансами в коммерческом банке // Вестник ИвГУ. 2014. № 1 (21). С. 71-75.

11. Алесина Н.В., Бабенко Д.А. Особенности формирования ресурсной политики банка // Вызовы и возможности фринансового обеспечения стабильного экономического роста (Финансы-2017) : материалы всероссийской научно-практической конференции. Севастополь, 2017. С. 71-75.

12. Мирошниченко О.С. Указ. соч.

13. Шатковская Е.Г. Указ. соч.

14. Там же. С. 1141.

15. Radic N. Shareholder Value Creation in Japanese Banking // Journal of Banking \& Finance. 2015. No. 52. P. 199-207. https://doi.org/10.1016/j.jbankfin.2014.09.014

16. Бибикова Е.А., Симонцева С.В. Финансовая политика коммерческого банка: значение, роль, принципы фрормирования // Вестник ИГЭУ. 2011. № 5. С. 70-73.

17. Орлова С.А., Ташанова Е.С. Указ. соч.

18. Симонцева С.В. Состав и содержание основных элементов финансовой политики коммерческого банка // Современные наукоемкие технологии. Региональное приложение. 2001. № 4 (28). С. 73-80.

19. Рисунок разработан автором

20. Таблица подготовлена автором.

\section{References:}

Alesina, NV \& Babenko, DA 2017, 'Features of the Formation of a Resource Policy of the Bank', Vyzovy $i$ vozmozhnosti finansovogo obespecheniya stabil'nogo ekonomicheskogo rosta (Finansy-2017): materialy vserossiyskoy nauchno-prakticheskoy konferentsii, Sevastopol, pp. 71-75, (in Russian).

Bibikova, EA \& Simontseva, SV 2011, 'The Financial Policy of a Commercial Bank: Value, Role, Principles of Formation', Vestnik IGEU, no. 5, pp. 70-73, (in Russian).

Chandler, AD 2003, Strategy and Structure. Chapters in the History of the American Industrial Enterprise, Washington, 480 p. Duvalova, EP 2012, 'Management of Financial Policy of a Commercial Bank as a Tool to Increase Its Market Sustainability', Kazanskiy ekonomicheskiy vestnik, no. 1 (1), pp. 57-62, (in Russian).

Godin, A \& Kurilov, R 2009, 'Resource Policy as the Basis of Bank Management', Vestnik Instituta ekonomiki RAN, no. 2, pp. 209-214, (in Russian).

Gryaznova, AG, Markina, EV \& Sedova, ML et al. 2012, Finance: a Textbook, $2^{\text {nd }}$ ed., Moscow, 496 p., (in Russian).

Miroshnichenko, OS 2014, 'Financial Policy of the Bank: Theoretical Aspects', Upravleniye ekonomicheskimi sistemami: elektronnyy zhurnal, no. 10, viewed 05 May 2019, <http://uecs.ru/finansi-i-kredit/item/3081-2014-10-16-07-58-30>, (in Russian). Orlova, SA \& Tashanova, ES 2018, 'Financial Policy of a Commercial Bank', Ekonomicheskaya sreda, no. 3 (25), pp. 50-54, (in Russian).

Radic, N 2015, 'Shareholder Value Creation in Japanese Banking', Journal of Banking \& Finance, no. 52, pp. 199-207, https://doi.org/10.1016/j.jbankfin.2014.09.014.

Scherbinin, AE 2009, 'The Strategy of Forming Liabilities in the Framework of the Resource Policy of a Regional Bank', Bankovskiye uslugi, no. 2, pp. 19-24, (in Russian).

Selevanova, EV \& Adamchuk, VS 2018, 'Resource Policy of Credit Institutions', Nauchnyye issledovaniya, no. 6 (26), pp. 4446, (in Russian).

Shatkovskaya, EG 2014, 'The System of Formation and Implementation of the Financial Policy of the Credit Organization', Fundamental'nyye issledovaniya, no. 11-5, pp. 1137-1142, (in Russian).

Simontseva, SV 2001, 'The Composition and Content of the Main Elements of the Financial Policy of a Commercial Bank', Sovremennyye naukoyemkiye tekhnologii. Regional'noye prilozheniye, no. 4 (28), pp. 73-80, (in Russian).

Simontseva, SV 2014, 'Financial Policy as a Basis for Financial Management in a Commercial Bank', Vestnik IVGU, no. 1 (21), pp. 71-75, (in Russian). 